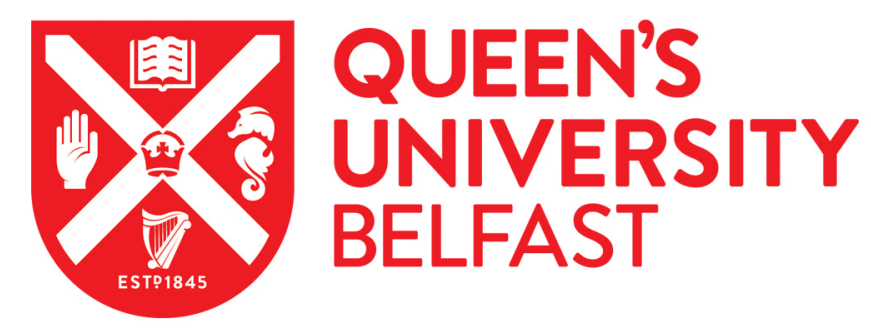

\title{
Thermal Properties of Choline Chloride/Urea System Studied under Moisture-Free Atmosphere
}

Gilmore, M., Swadzba-Kwasny, M., \& Holbrey, J. D. (2019). Thermal Properties of Choline Chloride/Urea System Studied under Moisture-Free Atmosphere. Journal of Chemical and Engineering Data, 64(12), 52485255. https://doi.org/10.1021/acs.jced.9b00474

Published in:

Journal of Chemical and Engineering Data

Document Version:

Peer reviewed version

Queen's University Belfast - Research Portal:

Link to publication record in Queen's University Belfast Research Portal

Publisher rights

(c) 2019 American Chemical Society.

This work is made available online in accordance with the publisher's policies. Please refer to any applicable terms of use of the publisher.

\section{General rights}

Copyright for the publications made accessible via the Queen's University Belfast Research Portal is retained by the author(s) and / or other copyright owners and it is a condition of accessing these publications that users recognise and abide by the legal requirements associated with these rights.

Take down policy

The Research Portal is Queen's institutional repository that provides access to Queen's research output. Every effort has been made to ensure that content in the Research Portal does not infringe any person's rights, or applicable UK laws. If you discover content in the Research Portal that you believe breaches copyright or violates any law, please contact openaccess@qub.ac.uk. 


\title{
Thermal properties of choline chloride:urea system studied under moisture-free atmosphere
}

\author{
Mark Gilmore, Malgorzata Swadzba-Kwasny* and John D. Holbrey* \\ The QUILL Research Centre, School of Chemistry and Chemical Engineering, Queen's \\ University of Belfast, Belfast, BT9 5AG, United Kingdom.
}

ABSTRACT: Physical chemistry of an archetypal deep eutectic solvent system, choline chloride:urea, was studied using dry components under moisture-free conditions. The phase diagram reveals that the eutectic melting point is $304.95 \mathrm{~K}$ (higher than any of the previously reported values to date), and a previously-unrecognised phase region in the solid-liquid phase diagram, corresponding to a $\mathrm{C} 1 \rightarrow \mathrm{C} 2$ transition $(351.62 \mathrm{~K}$ ) from $\alpha$-choline chloride to $\beta$-choline chloride. Viscosities and densities, measured for the eutectic composition as a function of temperature, were compared with all data available in the literature, and discrepancies are discussed. Thermal stability studies reveal that the eutectic composition undergoes a thermal decomposition at temperatures as low as $363.15 \mathrm{~K}$ (mass loss rate of $0.411 \mathrm{wt}^{0} \mathrm{~h}^{-1}$ ), which calls for a careful consideration when using these solvents at elevated temperatures. 


\section{Introduction}

The term deep eutectic solvent (DES) was introduced in 2003 by Abbott and co-workers. ${ }^{1}$ to describe low temperature liquids formed from mixtures of choline chloride with ureas. Although a formal definition has not been provided, DESs are typically mixtures of simple organic salts acting as hydrogen-bond acceptors (e.g. choline chloride) and small organic molecules acting as hydrogen bond donors (urea), which have the capacity to form a eutectic mixture, preferably liquid at room temperature. Using low-toxicity, off-the-shelf components, DESs provided an attractive low-cost and low-toxicity alternative to traditional ionic liquids, with a promising potential for industrial uses. ${ }^{2,3}$

The archetypical DES is the mixture of choline chloride and urea in 1:2 molar ratio $\left(\chi_{\mathrm{ChCl}}=\right.$ 0.33 ) and has been used in a wide range of applications, ${ }^{4}$ from metal electrodeposition, ${ }^{5}$ metalcatalysed organic synthesis ${ }^{6}$ and nanomaterial preparation ${ }^{7}$ to separations and extraction applications. ${ }^{8-11}$ Considering the breadth of applications, and the very specific meaning of the term "eutectic" in reference to physical chemistry, the key thermal analytical data for choline chloride:urea (ChCl:Ur) mixtures are surprisingly inconsistently reported across the literature. ${ }^{1,12-14}$ In particular, the melting points used to construct the phase diagram vary between papers, including the eutectic melting point. Furthermore, solid thermal stability data are scarce, and estimates of the thermal stability of this system are vastly different across the literature and, because $\mathrm{ChCl}: \mathrm{Ur}$ mixtures are often used of at elevated temperature to overcome their relatively high viscosities, understanding of its long-term stability is of key importance for practical application. 
With respect to the eutectic composition $\left(\chi_{\mathrm{ChCl}}=0.33\right)$, in the first paper on $\mathrm{ChCl}: \mathrm{Ur} \mathrm{DES},{ }^{1}$ the eutectic prepared by mixing at $353.15 \mathrm{~K}$ was found to freeze at $285.15 \mathrm{~K}$. The phase diagram was prepared using off-the-shelf components, without pre-drying, and the mixtures were reported to contain $<1 \mathrm{wt} \%$ water, determined by ${ }^{1} \mathrm{H}$ NMR spectroscopy. Considering the molecular weight differential between ChCl:2Ur $\left(259.76 \mathrm{~g} \mathrm{~mol}^{-1}\right)$ and $\mathrm{H}_{2} \mathrm{O}\left(18.01 \mathrm{~g} \mathrm{~mol}^{-1}\right)$, this corresponds to one $\mathrm{H}_{2} \mathrm{O}$ molecule for about seven $\mathrm{ChCl}$ :2Ur clusters, which is likely to have significant influence on properties. Another early phase diagram, constructed by Morrison et al., ${ }^{13}$ for $\mathrm{ChCl}: \mathrm{Ur}$ mixtures synthesised by solventless mixing at $373.15-423.15 \mathrm{~K}$. In contrast to Abbott et al., ${ }^{1}$ using differential scanning calorimetry (DSC) measuring from $213.15 \mathrm{~K}$ to 398.15 $\mathrm{K}$ with a temperature gradient of $1 \mathrm{~K} \mathrm{~min}^{-1}$, the melting point of the eutectic, determined from the DSC peak onset point, was found to be $290.15 \mathrm{~K}$.

Looking specifically at the influence of water on the ChCl:Ur DES, Shah et al. ${ }^{14}$ prepared the $\chi_{\mathrm{ChCl}}=0.33$ mixture from choline chloride and urea dried overnight in a vacuum oven (under unspecified conditions) adding both components to a vial (with no reference to the exclusion moisture) followed by mixing in a sealed vial at $353.15 \mathrm{~K}$ for $1 \mathrm{~h}$. This composition was assumed to be absolutely dry (literally described as having zero molecules of water present), although no analytical data were provided for water content, and reported to have a melting point of exactly $281.15 \mathrm{~K}$ from DSC measurement.

In the most rigorous study reported to date, ${ }^{12}$ described preparation of DES using starting materials dried under vacuum (10 $\mathrm{Pa}, 24 \mathrm{~h}$, room temperature) and then allowed to react at $353.15 \mathrm{~K}$ (no exclusion of moisture mentioned at this stage) to give residual water contents below 2000 ppm, and typically around 1000 ppm, measured by Karl-Fisher coulometry. The solidus temperature of the eutectic point was measured using a thermostatic bath, with cooling 
rates of 0.025 or $0.25 \mathrm{~K} \mathrm{~min}^{-1}$, were reported as 301.45 and $302.85 \mathrm{~K}$, respectively. The liquidus temperature, determined by observation using heated-stage polarised optical microscopy at the same ramp rates were 303.25 and $301.65 \mathrm{~K}$, respectively. Using DSC, only solidus transitions were observed at 296.65 and $297.65 \mathrm{~K}$ (for cooling rates of 0.025 or $0.25 \mathrm{~K} \mathrm{~min}^{-1}$,respectively) that were at lower temperatures that from the optical observations.

Strikingly, although most studies mention hygroscopic nature of this DES, there are no examples which have explicitly addressed the exclusion of moisture throughout the entire preparation and testing.

The viscosity of the ChCl:Ur eutectic $\left(\chi_{\mathrm{ChCl}}=0.33\right)$ is $2.1 \mathrm{~Pa}$ s at $293.15 \mathrm{~K}$, which is far greater than viscosities of many ionic liquids (for example, 1-ethyl-3-methylimidazolium triflate has viscosity of $0.05 \mathrm{~Pa}$ s at $293.15 \mathrm{~K}^{15}$ ), which additionally contributes to this DES being used at elevated temperatures, commonly above $373.15 \mathrm{~K} .{ }^{16}$ Solventless synthesis of the $\mathrm{ChCl}: \mathrm{Ur}$ system at $373.15-423.15 \mathrm{~K}$ have been reported ${ }^{13}$ and examples of high-temperature applications ${ }^{16-18}$ ranging from pre-treatment for the nanofibrillation of wood cellulose, ${ }^{18}$ as catalysts for chemical fixation of $\mathrm{CO}_{2}$ as cyclic carbonates, ${ }^{16}$ to ionothermal syntheses ${ }^{19-22}$ have been described. As such, these DES are often described as having high thermal stability, ${ }^{23-25}$ in analogy to ionic liquids. However, on the other hand, the thermal stability of pure urea is rather low: whereas thermogravimetric studies with relatively higher heating rates place the $T_{\mathrm{g}}$ close to the melting point (403.15-408.15 K), ${ }^{26}$ TGA studies at more moderate heating rates of $1 \mathrm{~K} \mathrm{~min}^{-1}$ show thermal decomposition from $378.15 \mathrm{~K}$. Although the thermal stability of ammonium halide:urea melts has been reported to be superior to that of pure urea, ascribed to formation of strong, stabilising hydrogen bonds, ${ }^{27}$ it should be evident that high-temperature applications must be approached with caution. Interestingly, this low thermal stability of $\mathrm{ChCl}$ :Ur DES has been 
acknowledged in some cases and uses to advantage - viz. ceria syntheses at 353.15-373.15 K, where urea decomposition is used to rationalise the reaction mechanism and outcome. ${ }^{19}$

In this contribution, we set out to report thermal analysis data for the $\mathrm{ChCl}$ :Ur system, with carefully controlled water content, adopting best practice in drying and moisture-free handling of the studied samples.

\section{Experimental}

A summary of the chemicals used in this study are provided in Table 1.

Table 1. CAS Registry Number, supplier, mass fraction purity, purification method and analysis of all chemicals used in this work

\begin{tabular}{|c|c|c|c|c|c|}
\hline Component & $\begin{array}{l}\text { CAS } \\
\text { Reg. } \\
\text { No. }\end{array}$ & Supplier & $\begin{array}{l}\text { Mass } \\
\text { fraction }\end{array}$ & $\begin{array}{l}\text { Further } \\
\text { purification }\end{array}$ & $\begin{array}{l}\text { Analysis } \\
\text { method }\end{array}$ \\
\hline $\begin{array}{l}\text { Choline chloride } \\
\text { ((2-hydroxyethyl)trimethyl- } \\
\text { ammonium chloride) }\end{array}$ & $\begin{array}{l}67-48- \\
1\end{array}$ & $\begin{array}{l}\text { Sigma- } \\
\text { Aldrich }\end{array}$ & 0.98 & $\begin{array}{l}\text { Dried under } \\
\text { vacuum }\end{array}$ & $\begin{array}{l}\text { 1H NMR, } \\
\text { TGA, DSC }\end{array}$ \\
\hline Urea & $\begin{array}{l}57-13- \\
6\end{array}$ & $\begin{array}{l}\text { Sigma- } \\
\text { Aldrich }\end{array}$ & $>0.99$ & $\begin{array}{l}\text { Dried under } \\
\text { vacuum }\end{array}$ & $\begin{array}{l}\text { 1H NMR, } \\
\text { TGA, DSC }\end{array}$ \\
\hline Methanol & $\begin{array}{l}67-56- \\
1\end{array}$ & $\begin{array}{l}\text { Fisher } \\
\text { Scientific }\end{array}$ & 0.998 & As received & $1 \mathrm{H} \mathrm{NMR}$ \\
\hline
\end{tabular}

\section{Preparation of choline chloride:urea mixtures}

Appropriate quantities of each component (Table 2) were combined in a $50 \mathrm{~cm}^{3}$ roundbottomed flask with a small quantity of methanol, then was stirred at ambient temperature (500 rpm) until a homogenous, colourless liquid formed. Methanol and traces of water were 
removed by evaporation in vacuo (overnight, $313.15 \mathrm{~K}, 1 \mathrm{~Pa}$ ). Products were closed under argon, moved to a glovebox (MBraun LabMaster dp, $<0.6$ ppm $\mathrm{O}_{2}$ and $\mathrm{H}_{2} \mathrm{O}$ ), and stored there until used.

Table 2. Quantities of components used to prepare each ChCl:Ur composition

\begin{tabular}{|c|c|c|}
\hline$\chi_{\mathrm{ChCl}}$ & Mass of $\mathrm{ChCl} / 10^{-3} \mathrm{~kg}$ & Mass of $\mathrm{Ur} / 10^{-3} \mathrm{~kg}$ \\
\hline 0.10 & 0.287 & 1.097 \\
\hline 0.20 & 0.407 & 0.687 \\
\hline 0.30 & 0.403 & 0.402 \\
\hline 0.33 & 3.003 & 2.576 \\
\hline 0.35 & 0.991 & 0.791 \\
\hline 0.40 & 1.011 & 0.645 \\
\hline 0.45 & 1.012 & 0.626 \\
\hline 0.50 & 0.804 & 0.343 \\
\hline 0.60 & 0.803 & 0.230 \\
\hline 0.67 & 0.810 & 0.170 \\
\hline 0.70 & 0.806 & 0.146 \\
\hline 0.80 & 1.007 & 0.100 \\
\hline 0.90 & 1.001 & 0.041 \\
\hline
\end{tabular}

\section{Water content analysis}


Water content was measured for samples that were liquid near ambient temperature, using a coulometric Karl Fisher titrator (Metrohm 899).

In the glovebox, $c a .0 .5 \mathrm{~cm}^{3}$ of each were drawn up into a $1 \mathrm{~cm}^{3}$ syringe, the tip of which was sealed with parafilm, and removed from the glovebox. Immediately before the measurement, the parafilm was removed and a needle was placed on the tip of the syringe. The sample-containing syringe was weighed, then approximately $0.10-0.25 \mathrm{~g}$ of the sample was injected into the KarlFisher titrator, and immediately after - the syringe was re-weighed to find the mass of the added drops. This mass was then entered into the titrator, to enable the water content to be determined as a mass fraction (in ppm).

\section{Solid-liquid phase transitions analysis}

Phase transitions were studied using differential scanning calorimetry (DSC) and polarised optical microscope (POM).

DSC experiments were performed using a TA Instruments DSC Q2000 fitted with RCS 90 cooling system. In the glovebox, samples were loaded into TA Tzero aluminium pans with TA Tzero hermetic lids. The sealed and removed from the glovebox. Masses of empty and filled pans were recorded ( $\pm 0.0002 \mathrm{~g})$, from which masses of samples were calculated. In a typical DSC experiment, minimum two scans were recorded, cycling the temperature between 233.15 and $353.15 \mathrm{~K}$, at 0.1 to $5 \mathrm{~K} \mathrm{~min}^{-1}$.

POM studies were carried out using an Olympus BX50 microscope fitted with Cannon 500D digital camera. Microscope slides containing DESs samples were prepared in the glovebox and sealed using high-vacuum silicone grease (Dow Corning). The samples were removed from the 
glovebox and placed on a Peltier stage, fitted with a thermocouple, heating, and liquid nitrogen cooling. The samples were cooled to $273.15 \mathrm{~K}$, at $c a .5 \mathrm{~K} \mathrm{~min}^{-1}$, held at this temperature for 5 min, then heated at $1 \mathrm{~K} \mathrm{~min}^{-1}$, until completely liquefied. Upon heating, the samples were observed through the microscope and digital images of the sample were periodically captured, with temperature noted for each image. The polarisable lenses on the microscope were used to detect birefringence in the sample (indicative of crystalline species). The onset of melting, phase transitions and liquidus points were recorded in duplicate.

Densities were measured using a vibrating tube densitometer Mettler Toledo DM40. In the glovebox, samples were taken up into a $5 \mathrm{~cm}^{3}$ syringe and sealed with parafilm, then the syringe was removed from the glovebox. Immediately before the sample was injected into the density meter the parafilm was removed. The syringe remained in the inlet during the measurement and the outlet was capped to ensure no atmospheric moisture could contact the sample during the measurement. Densities were measured within the temperature range of (293.15-363.15) K, at $10 \mathrm{~K}$ increments and $298.15 \mathrm{~K}$.

Viscosities were measured using a Bohlin Gemini cone and plate rotational rheometer. In the glovebox, samples were taken up into a $5 \mathrm{~cm}^{3}$ syringe and sealed with parafilm, then the syringe was removed from the glovebox. Immediately before the sample was placed onto the viscometer plate and covered with a cone, the parafilm was removed. Viscosities were measured within the temperature range of (293.15-368.15) K, at approximately $6 \mathrm{~K}$ increments. During the measurement, the edges of the sample sandwiched between the cone and the plate of the viscometer are exposed to the ambient atmosphere, however potential for absorption of moisture is minimised by the low contact area and short measurement times (ca. $5 \mathrm{~min}$ ). No abnormalities in the VFT fits of the data were observed. 


\section{Thermal stability analysis}

Thermal stability was investigated by thermogravimetric analysis (TGA), and the decomposition products characterised using headspace GC-MS.

TGA curves were recorded using TA Instruments TGA Q5000. The masses of single-use TA aluminium cup and a TA aluminium lid were recorded using the TGA microbalance $( \pm 0.0000001 \mathrm{~g})$, which was then tared. The pans were transferred into the glovebox, filled with $\mathrm{ChCl}: \mathrm{Ur}$ samples and sealed. Once removed from the glovebox, the pans were placed in the TGA autosampler carousel. The lid of each pan was pierced individually, $30 \mathrm{~s}$ before use. All measurements were carried out under a stream of dry nitrogen $\left(20 \mathrm{~cm}^{3} \mathrm{~min}^{-1}\right)$ at a rate of $5 \mathrm{~K}$ $\mathrm{min}^{-1}$. Dynamic TGA curves were recorded once heating a sample from 298.15-673.15 K, at $5 \mathrm{~K}$ $\min ^{-1}$. Isothermal TGA curves were recorded by heating each sample to $363.15 \mathrm{~K}\left(5 \mathrm{~K} \mathrm{~min}^{-1}\right)$ and holding at this temperature for $6 \mathrm{~h}$.

GC-MS analyses were recorded using a Perkin Elmer Clarus 500. In the glovebox, the sample of the eutectic was placed in a GC vial and crimped. Then, it was placed in a sand bath standing on a hotplate in the glovebox and held at $363.15 \mathrm{~K}$ for $24 \mathrm{~h}$. Finally, the vial was removed from the glovebox and the headspace gases were analysed using the GC-MS.

Estimated uncertainties for measurements are provided in Table 3.

Table 3. Estimated uncertainties in measurements

\begin{tabular}{ll}
\hline Measurement & Estimated uncertainty \\
\hline Samples preparation & 0.005 \\
Density & 0.003
\end{tabular}


Viscosity

0.035

DSC

$1.0 \mathrm{~K}$

TGA

$1.0 \mathrm{~K}$

POM

$1.5 \mathrm{~K}$

\section{Results and discussion}

\section{Sample preparation and water content analysis}

In the case of DES, solventless syntheses are without a doubt a more sustainable route than those using a solvent. However, for the purpose of thermal analyses, it was decided to use small amount of methanol to solubilise components of the $\mathrm{ChCl}$ :Ur mixtures, thereby eliminating the need for excessive heat. Initially overnight drying of samples under reduced pressure at 353.15 $\mathrm{K}$, resulted in deposition of white crystals around the top of round-bottomed flasks used (Figure 1). The solid was identified as urea by NMR spectroscopy. Consequently, the lower drying temperature of $313.15 \mathrm{~K}$ was subsequently used. ${ }^{1} \mathrm{H}$ NMR spectra and TGA curves of the products dried at $313.15 \mathrm{~K}$ showed no traces of methanol.

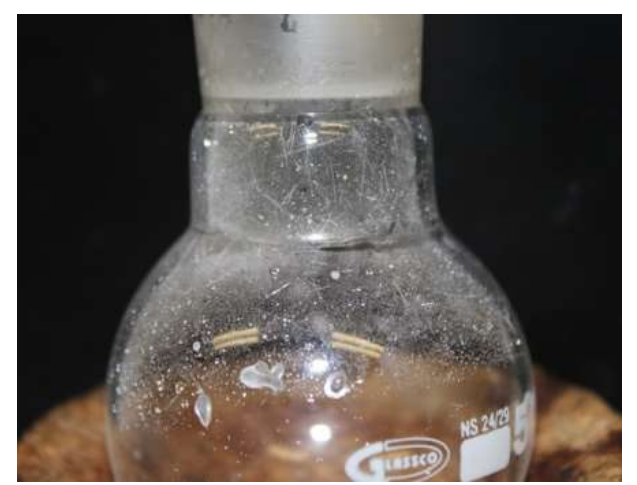


Figure 1. Urea crystals deposited on the neck of the flask after overnight drying at $353.15 \mathrm{~K}$, under reduced pressure.

Thirteen samples were prepared, of which the four compositions between $\chi \mathrm{ChCl}=0.33-0.45$ were homogenous liquids at ambient conditions, and a further three readily melted forming homogenous liquids at slightly elevated temperature (Table 4). Moisture contents of these sample compositions were measured in duplicate, using a Karl-Fisher coulometer (Table 4). Water contents (Table 4) ranged from 100 to $500 \mathrm{ppm}(<300 \mathrm{ppm}$ on average, with a variance of $10-1400 \mathrm{ppm}$ between replicate measurements on the same samples) and did not appear to corelate with DES composition $\left(\chi_{\mathrm{ChCl}}\right)$. In general, water content was an order of magnitude lower than that reported by Meng et $a l .{ }^{12}$

Table 4. Water content and appearance at ambient conditions of $\mathrm{ChCl}: \mathrm{Ur}$ samples

\begin{tabular}{lllll}
\hline \multirow{2}{*}{$\begin{array}{l}\text { KChCl } \\
\end{array}$} & Appearance & \multicolumn{2}{l}{ Karl-Fisher results /ppm water } \\
\cline { 3 - 5 } & & Run 1 & Run 2 & Average \\
\hline 0.20 & Solid & 260 & - & 260 \\
0.30 & Solid/liquid suspension & 500 & 440 & 470 \\
0.33 & Liquid & 60 & 170 & 115 \\
0.35 & Liquid & 310 & 460 & 385 \\
0.40 & Liquid & 120 & 220 & 170 \\
0.45 & Liquid & 450 & 440 & 445 \\
0.50 & Gelatinous solid & 70 & 140 & 105 \\
\hline
\end{tabular}




\section{Phase diagram}

DSC scans for two $\mathrm{ChCl}: \mathrm{Ur}$ compositions, $\chi_{\mathrm{ChCl}}=0.33$ and 0.67 , were recorded at three different scan rates: $0.1,1.0$ and $5.0 \mathrm{~K} \mathrm{~min}^{-1}$. At the highest rate of $5 \mathrm{~K} \mathrm{~min}^{-1}$ no phase transitions were detected for the eutectic composition, and was ascribed to supercooling and subsequent glass formation (Figure 2). Reducing the scan rate to $1 \mathrm{~K} \mathrm{~min}^{-1}$ resulted in a broad feature during the heating cycle associated with cold-crystallisation followed by melting. On further reduction of the temperature scan rate to $0.1 \mathrm{~K} \mathrm{~min}^{-1}$, a two-step melting event for the $\chi_{\mathrm{ChCl}}=0.33$ composition was observed; however, this slow scan rate significantly increases the experiment time significantly to the point of impracticability (33 $\mathrm{h}$ for a single cooling/heating cycle). We speculate that the very low water contents result in increased viscosity and decreased molecular mobility in the DES, making it less likely to rearrange into a crystalline form, and more likely to glass formation.

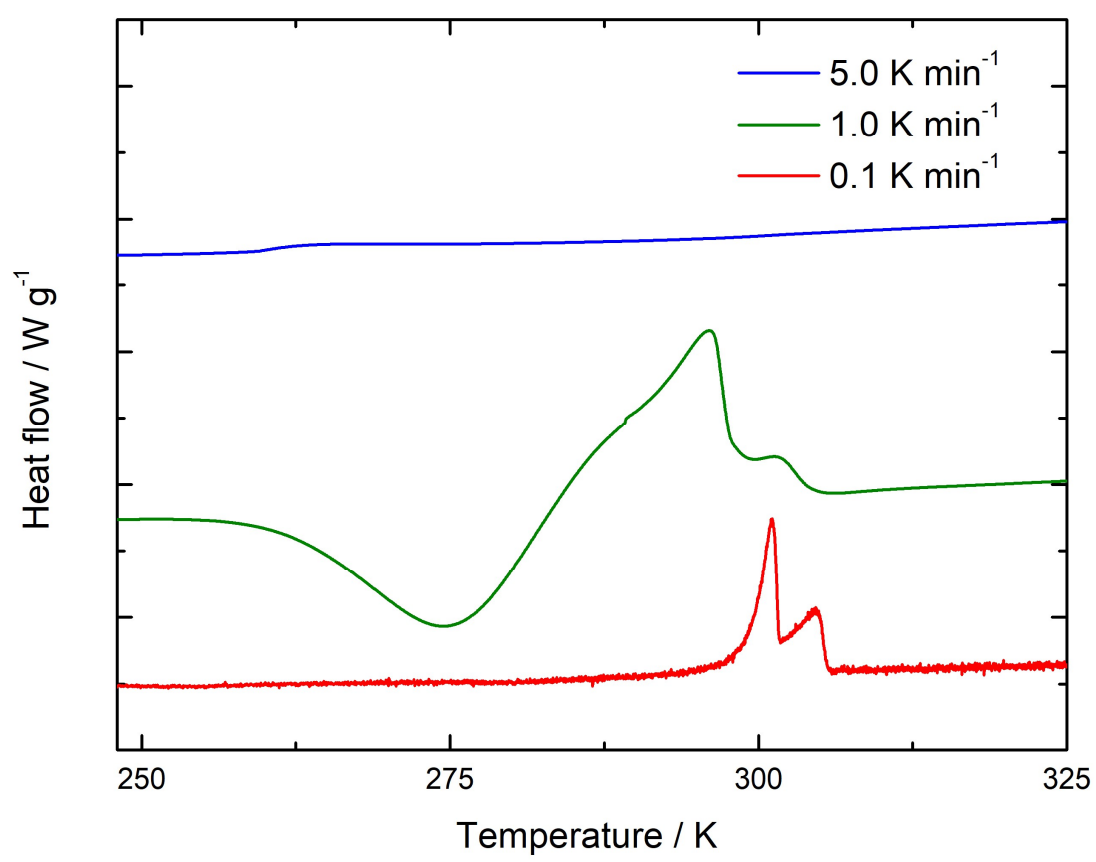


Figure 2. Fragments of DSC scans (heating) recorded for: $\chi_{\mathrm{ChCl}}=0.33$ at $0.1 \mathrm{~K} \mathrm{~min}^{-1}(-), 1.0 \mathrm{~K}$ $\min ^{-1}(-)$ and $5.0 \mathrm{~K} \mathrm{~min}^{-1}(-)$. Exo down.

Since DSC was unsuitable to identify transition points necessary for construction of the phase diagram, it was decided to use POM instead. Phase transitions were marked as the temperatures at which the transition was complete (typically within $2 \mathrm{~K}$ from the event onset), these are listed in Table 5.

Table 5. Phase transition points of ChCl:Ur samples, derived from $\mathrm{POM}$ experiments at $99.5 \mathrm{kPa}^{a}$

\begin{tabular}{|c|c|c|}
\hline \multirow[t]{2}{*}{$\chi_{\mathrm{ChCl}}$} & \multicolumn{2}{|c|}{ Temperature of phase transitions $\mathrm{T} / \mathrm{K}$} \\
\hline & eutectic phase melting & phase transition 2 \\
\hline 0.10 & - & 398.25 \\
\hline 0.20 & - & 376.95 \\
\hline 0.30 & 305.35 & 350.75 \\
\hline 0.33 & - & 305.85 \\
\hline 0.35 & 303.95 & 314.55 \\
\hline 0.40 & 303.25 & 341.75 \\
\hline 0.45 & 303.75 & 352.45 \\
\hline 0.50 & 307.95 & 351.75 \\
\hline 0.60 & 307.45 & 352.25 \\
\hline 0.67 & 305.15 & 349.55 \\
\hline 0.70 & - & 351.05 \\
\hline 0.80 & - & 351.55 \\
\hline
\end{tabular}


${ }^{a}$ The standard uncertainty, $u$, of phase transition temperatures, $T$, and pressure, $P$, are $u(T)=$ $1.5 \mathrm{~K}$ and $u(P)=1.0 \mathrm{kPa}$

The literature reported melting points of choline chloride $(575.15 \mathrm{~K})$ and urea $(407.15 \mathrm{~K}),{ }^{1,12}$ fit well with the data recorded here. The eutectic point was found at $\chi_{\mathrm{ChCl}}=0.33$, in agreement with previous studies of this DES. ${ }^{1,12-14}$ However, the eutectic composition was found to melt at $304.95 \mathrm{~K}\left(T_{1}\right.$, Figure 3$)$, which is higher than values previously reported. Furthermore, a previously unreported solid-solid transition in the choline-rich side $(\chi \mathrm{ChCl}=0.45-0.90)$ of the phase diagram was observed, with a phase transition point of $351.62 \mathrm{~K}\left(T_{2}\right.$, Figure 3$)$.

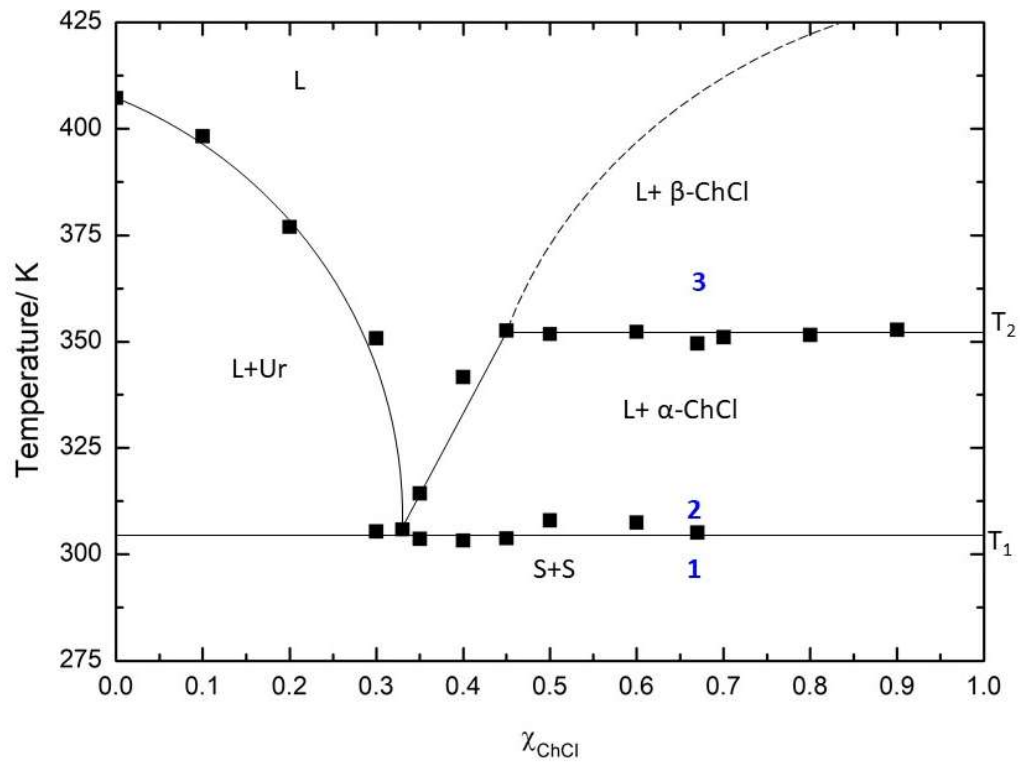

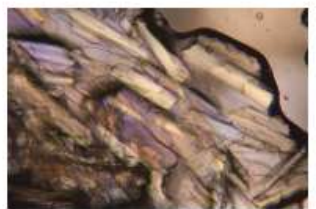

1

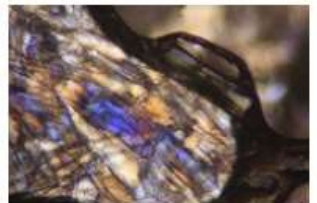

2

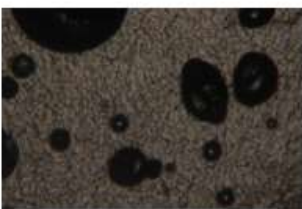

3 
Figure 3. Phase diagram of ChCl:urea, accompanied by $\mathrm{POM}$ images of the $\chi_{\mathrm{ChCl}}=0.67$ sample, captured at 1) $298.15 \mathrm{~K}$, 2) $308.15 \mathrm{~K}$ and 3) $353.15 \mathrm{~K}$. Crystallites shown in the figure are up to 1 mm of length.

Since the new phase was previously unreported, the transition was also confirmed via DSC measurement and was found to have an enthalpy of $\Delta H=43.35 \mathrm{~kJ} \mathrm{~kg}^{-1}$, with a relative standard uncertainty $u_{r}(\Delta H)=0.015$ for the $\chi_{\mathrm{ChCl}}=0.67 \mathrm{ChCl}$ :Ur sample (Figure 4).

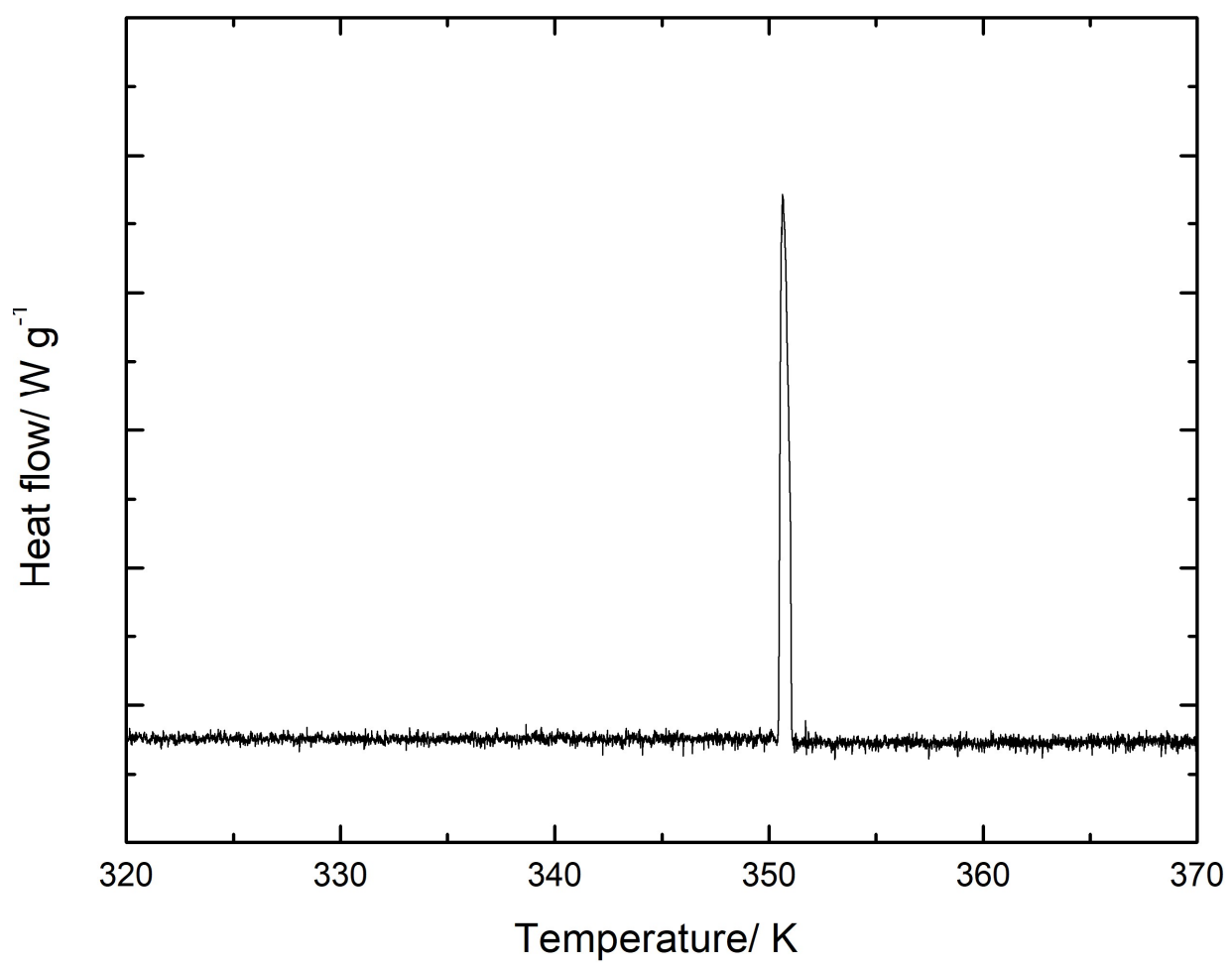

Figure 4. $\mathrm{DSC}$ scan showing the solid-solid $\mathrm{ChCl}$ transition in the $\chi_{\mathrm{ChCl}}=0.67$ composition mixture at $0.1 \mathrm{~K} \mathrm{~min}^{-1}$. Exo down.

The urea-rich samples $\left(\chi_{\mathrm{ChCl}}<0.30\right)$ are mixtures containing an amorphous liquid phase and a crystalline solid and exhibits a single melting at elevated temperatures. Within the composition range $\chi_{\mathrm{ChCl}}=0.30$ to 0.45 , two phase transitions are observed as expected, the initial melting of 
the eutectic and the subsequent clearing of the solid + liquid mixtures with the exception of the eutectic point at $\chi_{\mathrm{ChCl}}=0.33$ (single melting point at $T_{1}=304.95 \mathrm{~K}$ ). At temperatures above the respective second phase transition, all samples formed homogenous liquids. In the third region, $\chi_{\mathrm{ChCl}}=0.50$ to 0.67 , there were three crystalline phases: the eutectic melting slightly below $305.15 \mathrm{~K}$; the $\alpha-\mathrm{ChCl}$ phase, transitioning at $c a .351 .62 \mathrm{~K}$ to $\beta-\mathrm{ChCl}^{28}$ and $\beta-\mathrm{ChCl}$ in the form of weakly crystalline powder, co-existing with a liquid phase. As expected, $\beta-\mathrm{ChCl}$ crystals did not melt until thermal decomposition was observed under the microscope in the form of bubbles of gas (reaching complete decomposition ca. $533.15 \mathrm{k}$ ).

POM images of the three phases observed in the $\chi_{\mathrm{ChCl}}=0.67$ sample are shown in Figure 3 . At 298.15 K, the sample appears as a single solid phase (Figure 3,1). When the temperature of the sample is increased to $308.15 \mathrm{~K}$, melting of the eutectic portion occurs at $T_{1}$, and the sample contains a liquid and crystalline birefringent $\alpha-\mathrm{ChCl}^{28}$ particles under crossed polarisers (Figure 3, 2). Upon heating to $353.15 \mathrm{~K}$, the crystalline portion of the solid + liquid mixture at $T_{2}$ undergoes a solid-solid transformation generating a new phase $(\beta-\mathrm{ChCl})^{28}$ dispersed in a liquid (Figure 3, 3).

\section{Physical properties}

The $\mathrm{ChCl}: \mathrm{Ur}$ system is extremely hydroscopic and it has been shown that the eutectic composition exposed directly to the atmosphere will eventually absorb up to $19 \%$ of water (by mass). ${ }^{12}$ As with ionic liquids, lack of control over water content will affect physical properties, with viscosity being much more susceptible to variation than density. ${ }^{29}$ 
Viscosity and density of the $\mathrm{ChCl}: \mathrm{Ur}$ eutectic $\left(\chi_{\mathrm{ChCl}}=0.33\right)$ were measured here with exclusion of moisture. The results are shown in Table 6 and are compared to the literature. ${ }^{14,30,31,1}$ Densities measured in this work fit to the linear relationship in Equation (1), where $a=-5.486 \mathrm{~g} \mathrm{~cm}^{-1} \mathrm{~K}^{-1}$ and $b=1.213 \mathrm{~g} \mathrm{~cm}^{-1}, \mathrm{R}^{2}=1.000$.

$d=a T+b$

Table 6. Viscosities and densities of the ChCl:Ur eutectic $\left(\chi_{\mathrm{ChCl}}=0.33\right)$ as a function of temperature at $99.5 \mathrm{kPa}^{a}$

\begin{tabular}{llll}
\hline $\mathbf{T} / \mathbf{K}$ & $\boldsymbol{\eta} / \mathbf{P a} \cdot \mathbf{S}$ & $\mathbf{T} / \mathbf{K}$ & $\boldsymbol{\rho} / \mathbf{g ~ c m}^{-3}$ \\
\hline 293.25 & 2.110 & 293.15 & 1.203 \\
299.45 & 1.286 & 303.15 & 1.197 \\
305.85 & 0.725 & 313.15 & 1.192 \\
312.15 & 0.432 & 323.15 & 1.186 \\
318.35 & 0.265 & 333.15 & 1.180 \\
324.55 & 0.170 & 343.15 & 1.175 \\
330.95 & 0.116 & 353.15 & 1.170 \\
337.15 & 0.083 & 363.15 & 1.164 \\
343.35 & 0.061 & - & - \\
349.55 & 0.046 & - & - \\
355.85 & 0.036 & - &
\end{tabular}


362.05

368.25

0.021

${ }^{a}$ Standard uncertainties, $u$, of $T, P, \eta$ and $\rho$ are $u(T)=1.0 \mathrm{~K}, u(P)=1.0 \mathrm{kPa}, u_{r}(\eta)=0.035$ and $u_{r}(\rho)=0.003$

These results are in a general agreement with those reported by Pandey and Yadav, ${ }^{30} \mathrm{Xie}$ et $a l .{ }^{31}$ and Su et al., ${ }^{32}$ with the average density at $303.15 \mathrm{~K}$ being $1.196 \pm 0.001 \mathrm{~g} \mathrm{~cm}^{-1}$. In contrast, densities reported by Shah et al. $\left(1.216 \mathrm{~g} \mathrm{~cm}^{-1}\right.$ at $\left.303.15 \mathrm{~K}\right)$ and Abbott and co-workers ${ }^{1}$ (Figure 5) are substantially higher. This coincides with their report of the eutectic melting/freezing point at about $285.15 \mathrm{k}$, which could be related to the high water content in these samples at the time of the measurement. However, doping the DES with water has been reported to lower densities, rather than increase them, ${ }^{14}$ therefore the origin of such discrepancies remain unclear. 


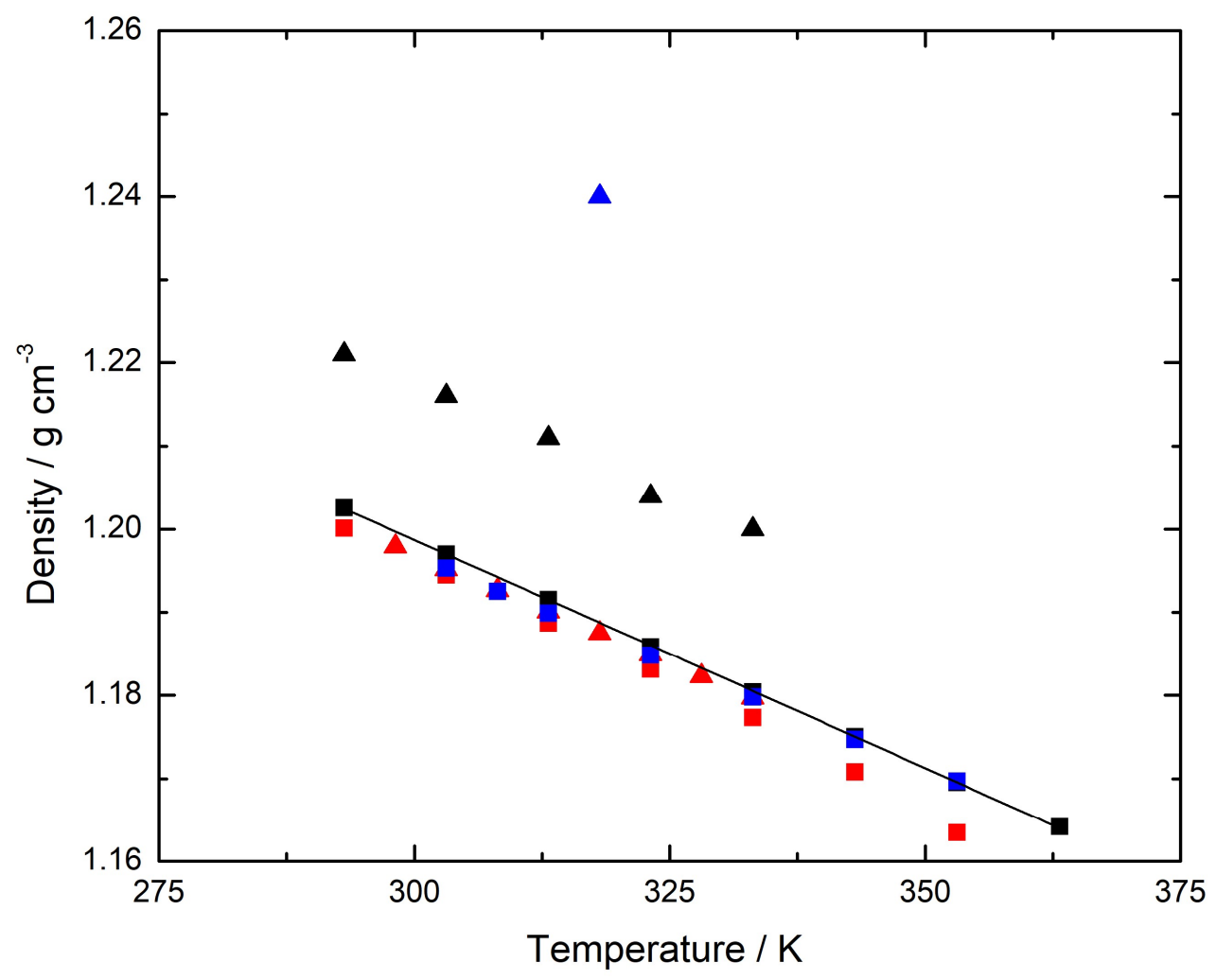

Figure 5. Comparison of density data recorded for the $\mathrm{ChCl}$ :Ur eutectic $\left(\chi_{\mathrm{ChCl}}=0.33\right)$ as a function

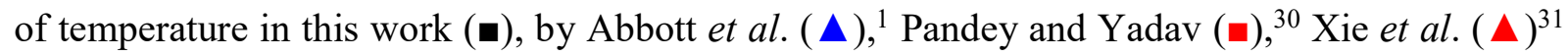
Shah et al. $(\mathbf{\Delta})^{14}$ and Su et al. (घ). ${ }^{32}$

Viscosities were fitted with a modified VFT Equation (2), where $C=6.792, K=1372.087, T_{0}$ $=218.3 \mathrm{~K}, R^{2}=0.998$.

$$
\eta=C T^{1 / 2} \exp \left(\frac{K}{T-T_{0}}\right)
$$

The viscosities measured here are comparable to the results reported by Xie et al., ${ }^{31}$ and are higher than those previously reported by Pandey et al..$^{30}$ and Abbott and co-workers ${ }^{1}$ (Figure 6). This is consistent with reduced viscosities associated with the presence of water in the latter materials. 


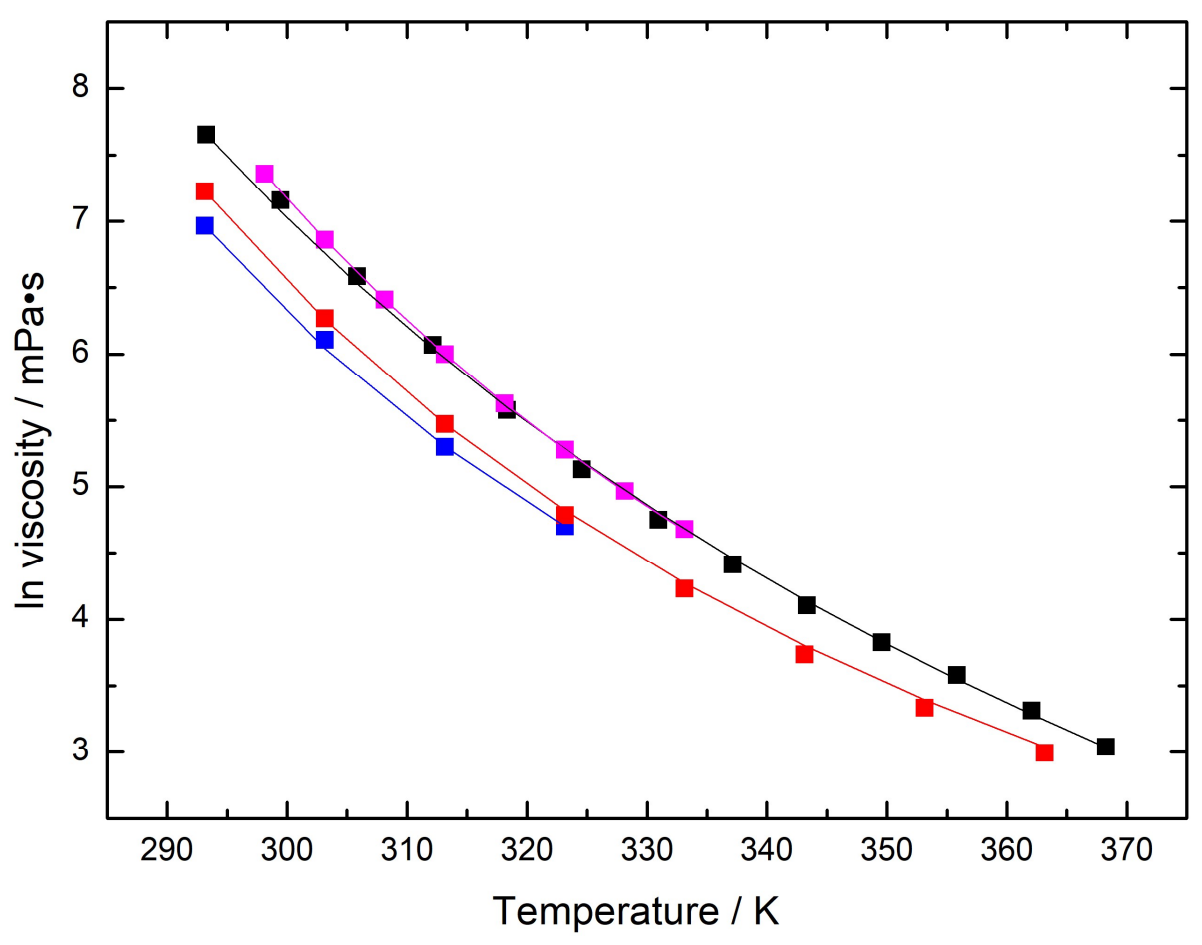

Figure 6. Literature comparison of $\ln$ viscosity as a function of temperature for the $\chi_{\mathrm{Chcl}}=0.33$

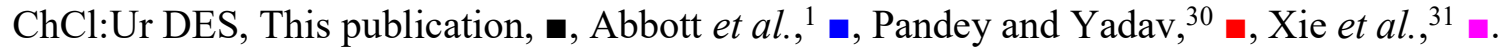

\section{Thermal stability}

Samples of $\mathrm{ChCl}: \mathrm{Ur}$ exposed to elevated temperatures (353.15-363.15 k) for prolonged periods of time have a strong ammoniacal odour, and crystalline solids deposit around the tops of vessels that the materials are stored in. These observations were the basis of the initial assumption that the thermal stability of the $\mathrm{ChCl}$ :Ur DES is poor. Thermal stability was studied in detail using TGA at the two $\mathrm{ChCl}$ :Ur compositions, $\chi_{\mathrm{ChCl}}=0.33$ and 0.67 (Figure 7). 


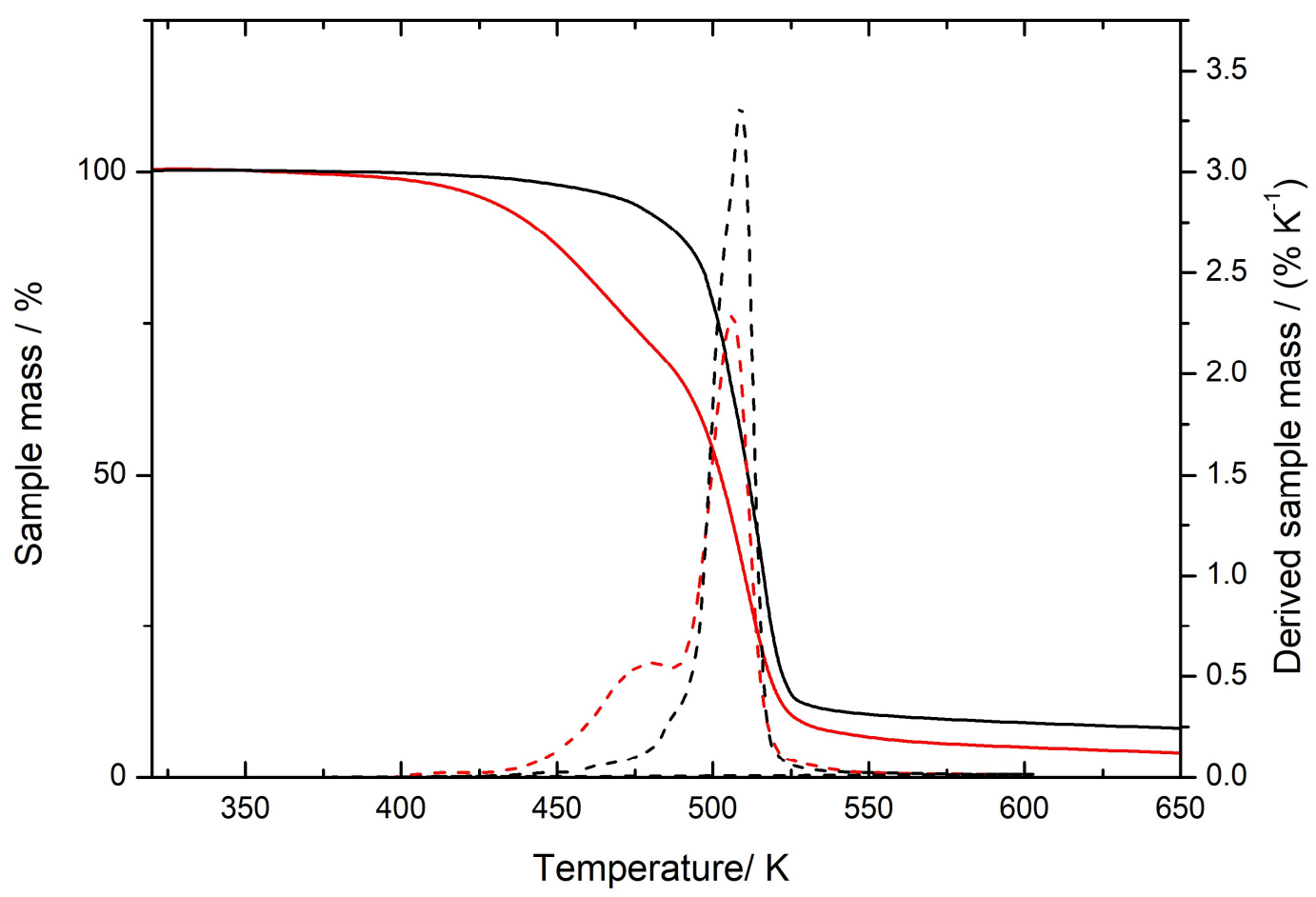

Figure 7. Dynamic TGA and DTG curves, recorded at $5 \mathrm{~K} \mathrm{~min}^{-1}$ for two samples of $\mathrm{ChCl}: \mathrm{Ur}$, $\chi_{\mathrm{ChCl}}=0.33(-)$, and $\chi_{\mathrm{ChCl}}=0.67(-)$, and derived mass loss for $\chi_{\mathrm{ChCl}}=0.33(--)$ and $\chi_{\mathrm{ChCl}}=0.67$ $(---)$.

The eutectic composition $\left(\chi_{\mathrm{ChCl}}=0.33\right)$, with the higher urea content, exhibits lower thermal stability. Thermal decomposition follows a two-step decomposition pathway, with DTG maxima at 467.15 and $510.15 \mathrm{k}$, starting with an onset attributed to decomposition of urea $\left(T_{\mathrm{d}}=358.15\right.$ k). The choline chloride-rich sample $\left(\chi_{\mathrm{ChCl}}=0.67\right)$ appears to contain only a single stage to decomposition, and this has a slightly higher decomposition onset $\left(T_{\mathrm{d}}=383.15 \mathrm{~K}\right)$, and DTG maximum of $515.15 \mathrm{~K}$, which is close to the second maximum in the eutectic composition. These results are in keeping with reports that urea has greater thermal stability in quaternary ammonium salt/urea mixtures. ${ }^{33}$ A comparative summary of thermal data derived from both curves is given in Table 7. 
Table 7. TGA analyses of two samples of $\mathrm{ChCl}$ : urea DES: $\chi \mathrm{Chcl}=0.33$ and $0.67^{\mathrm{a}}$

\begin{tabular}{llc}
\hline Thermal event & $\chi_{\text {Chcl }}=\mathbf{0 . 3 3}$ & $\chi_{\text {Chcl }}=\mathbf{0 . 6 7}$ \\
\hline Dynamic heating $\left(5 \mathrm{~K} \mathrm{~min}^{-1}\right)$ & & \\
\hline Onset of decomposition (K) & 358.15 & 383.15 \\
$5 \%$ mass loss (K) & 429.15 & 473.15 \\
DTG maxima (K) & $467.25,510.15$ & 515.15 \\
Final temperature (K) & 513.15 & 523.15 \\
\hline Isothermal scan (363.15 K) & & 0.067 \\
\hline Decomposition rate $\left(\% \mathrm{~h}^{-1}\right)$ & 0.411 & 62 \\
Time to full decomposition (days) & 10 &
\end{tabular}

Standard uncertainty for decomposition temperature $u(\mathrm{~T})=1.0 \mathrm{~K}$

Subsequently, isothermal TGA experiments were carried out to determine the stability ChCl:Ur at $363.15 \mathrm{~K}$ over $6 \mathrm{~h}$ (Figure 8). Decomposition rates were calculated based the mass loss in the linear components of the thermal analysis curves (Table 7). Mass loss from the eutectic composition was an order of magnitude faster than that from the choline chloride-rich sample and could be extrapolated to complete decomposition over only 10 days. Both samples show poor thermal stability $363.15 \mathrm{~K}$, in terms of practical applications. 


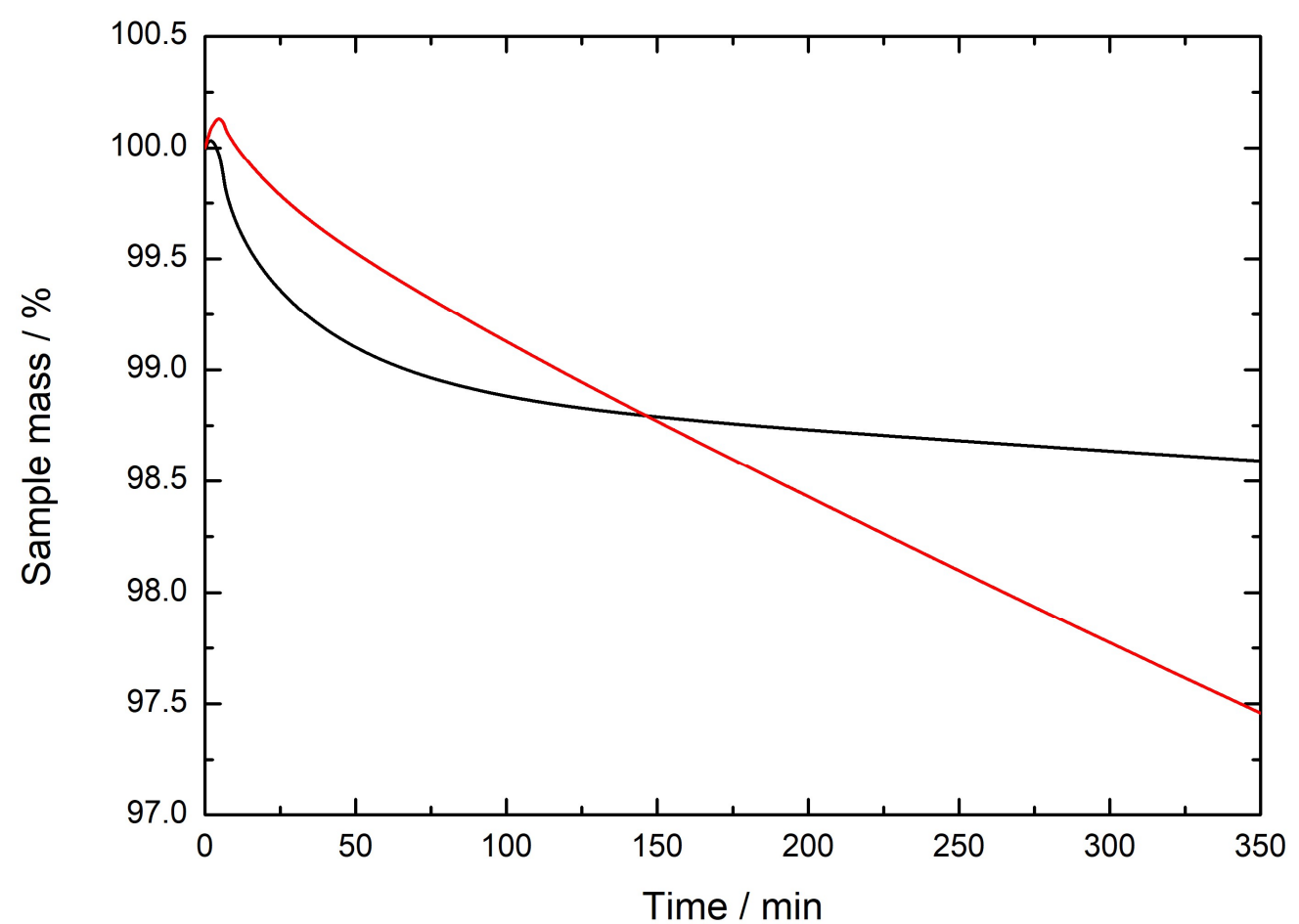

Figure 8. Isothermal TGA curves, recorded at $363.15 \mathrm{~K}$ for two samples of $\mathrm{ChCl}: \mathrm{Ur}$, $\chi_{\mathrm{ChCl}}=0.33(-)$, and $0.67(-)$.

The origin of the observed mass loss can be thermal decomposition (also through interaction of DES components), sublimation and or evaporation, of either pure components or reaction products. Unlike in DES based on $\mathrm{ChCl}$ :carboxylic acid mixtures, ${ }^{34}$ where components undergo esterification (accelerated at higher temperatures), there was no reaction observed in this system. However, thermal decomposition of urea to ammonia and biuret is firmly established. ${ }^{35}$ Similarly, ammonia generation from aqueous urea solutions has also been reported. ${ }^{26}$ Both of these results appear consistent with the first step of decomposition pathway suggested for the $\mathrm{ChCl}: \mathrm{Ur}$ eutectic, which is marked by ammoniacal odour. In order to confirm this, the gasses evolved from a sealed sample of ChCl:Ur eutectic $\left(\chi_{\mathrm{ChCl}}=0.33\right)$ heated at $363.15 \mathrm{~K}$ for $24 \mathrm{~h}$, 
were analysed by GC-MS. The main component of the gaseous decomposition products was found to be ammonia $(\mathrm{m} / \mathrm{z}=17)$.

\section{Conclusions}

A phase diagram for the low-moisture content $\mathrm{ChCl}$ :Ur system was constructed across the full compositional range using DSC and POM to characterise the transitions. DSC gave very limited insight into the phase behaviour, but more informative results were recorded using POM. The eutectic melting point was found at $304.95 \mathrm{~K}$, and a second phase transition, occurring at 351.62 $\mathrm{K}$, was observed in the choline chloride-rich composition space and assigned as a crystal-crystal transformation from $\alpha-\mathrm{ChCl}$ to $\beta-\mathrm{ChCl}^{28}$

Viscosities and densities, measured for the eutectic composition as a function of temperature, were consistent with some literature reports, ${ }^{31,32}$ but were at odds with studies carried out on samples that were not dried. ${ }^{1,14,30}$

Thermal stability of two $\mathrm{ChCl}: \mathrm{Ur}$ compositions: the eutectic $\left(\chi_{\mathrm{ChCl}}=0.33\right)$, and a choline chloride-rich sample $\left(\chi_{\mathrm{ChCl}}=0.67\right)$, was studied using TGA. Dynamic studies at $5 \mathrm{~K} \mathrm{~min}^{-1}$ revealed low decomposition onset in both samples, 358.15 and $383.15 \mathrm{~K}$, respectively. Isothermal studies have further confirmed thermal instability of both samples, with decomposition rates at $363.15 \mathrm{~K}$ of 0.411 and 0.067 mass \% per hour.

\section{Acknowledgements}

All authors thank Mrs Angela Brownlie for assistance with viscosity measurements and $\mathrm{Mr}$ Phillip McCarron for GC-MS measurements. 


\section{AUTHOR INFORMATION}

\section{Corresponding Author}

*E-mail: j.holbrey@qub.ac.uk

*E-mail: m.swadzba-kwasny@qub.ac.uk

\section{ORCID}

Mark Gilmore: 0000-0003-3314-592X

Malgorzata Swadzba-Kwasny: 0000-0003-4041-055X

John D. Holbrey: 0000-0002-3084-8438

\section{Funding}

The authors acknowledge funding and support from the QUILL Research Centre (to MG).

\section{Notes}

The authors declare no competing financial interest.

\section{REFERENCES}

(1) Abbott, A. P.; Capper, G.; Davies, D. L.; Rasheed, R. K.; Tambyrajah, V. Novel Solvent Properties of Choline Chloride/Urea Mixtures. Chem. Commun. (Camb). 2003, 1, 70-71.

(2) Alonso, D. A.; Chinchilla, R.; Pastor, I. M.; Ramón, D. J. Deep Eutectic Solvents : The Organic Reaction Medium of the Century. European J. Org. Chem. 2016, 612-632.

(3) Škulcová, A.; Majová, V.; Šima, J.; Jablonský, M. Mechanical Properties of Pulp 
Delignified by Deep Eutectic Solvents. BioResources 2017, 12 (4), 7479-7486.

(4) Smith, E. L.; Abbott, A. P.; Ryder, K. S. Deep Eutectic Solvents (DESs) and Their Applications. Chem. Rev. 2014, 114 (21), 11060-11082.

(5) Abbott, A. P.; Ttaib, K. El; Frisch, G.; Mckenzie, K. J.; Ryder, K. S. Electrodeposition of Copper Composites from Deep Eutectic Solvents Based on Choline Chloride. Phys. Chem. Chem. Phys. 2009, 11, 4269-4277.

(6) Garcia-Alvarez, J. Deep Eutectic Mixtures : Promising Sustainable Solvents for MetalCatalysed and Metal-Mediated Organic. Eur. J. Inorg. Chem. 2015, 31, 5147-5157.

(7) Wagle, D. V; Zhao, H.; Baker, G. A. Deep Eutectic Solvents: Sustainable Media for Nanoscale and Functional Materials. Acc. Chem. Res. 2014, 47, 2299-2308.

(8) Guo, W.; Wu, W.; Ren, S.; Tian, S.; Marsh, K. N. Separation of Phenol from Model Oils with Quaternary Ammonium Salts via Forming Deep Eutectic Solvents. Green Chem. 2013, $15,226-229$.

(9) Garcia, G.; Aparicio, S.; Ullah, R.; Atilhan, M. Deep Eutectic Solvents: Physicochemical Properties and Gas Separation Applications. Energy \& Fuels 2015, 29, 2616-2644.

(10) Pang, K.; Hou, Y.; Wu, W.; Guo, W.; Marsh, K. N. Efficient Separation of Phenols from Oils via Forming Deep Eutectic Solvents. Green Chem. 2012, 14, 2398-2401.

(11) Jablonský, M.; Andrea, Š.; Kamenská, L.; Vrška, M.; Šima, J. Deep Eutectic Solvents : Fractionation of Wheat Straw. BioResources 2015, 10 (4), 8039-8047.

(12) Meng, X.; Ballerat-Busserolles, K.; Husson, P.; Andanson, J.-M. Impact of Water on the 
Melting Temperature of Urea + Choline Chloride Deep Eutectic Solvent. New J. Chem. 2016, $40(5), 4492-4499$.

(13) Morrison, H. G.; Sun, C. C.; Neervannan, S. Characterization of Thermal Behavior of Deep Eutectic Solvents and Their Potential as Drug Solubilization Vehicles. Int. J. Pharm. 2009, $378(1-2), 136-139$.

(14) Shah, D.; Mjalli, F. S. Effect of Water on the Thermo-Physical Properties of Reline : An Experimental and Molecular Simulation Based Approach. Phys. Chem. Chem. Phys. 2014, $16,23900-23907$.

(15) Seddon K, Stark A, T. M. Viscosity and Density of 1-Alkyl-3-Methylimidazolium Ionic Liquids. In Clean Solvents; 2002; pp 34-49.

(16) Zhu, A.; Jiang, T.; Han, B.; Zhang, J.; Xie, Y.; Ma, X. Supported Choline Chloride / Urea as a Heterogeneous Catalyst for Chemical Fixation of Carbon Dioxide to Cyclic Carbonates. Green Chem. 2007, 9 (2), 169-172.

(17) Yadav, U. N.; Shankarling, G. S. Synergistic Effect of Ultrasound and Deep Eutectic Solvent Choline Chloride - Urea as Versatile Catalyst for Rapid Synthesis of $\beta$ Functionalized Ketonic Derivatives. J. Mol. Liq. 2014, 195, 188-193.

(18) Sirviö, J. A.; Visanko, M.; Liimatainen, H. Deep Eutectic Solvent System Based on Choline Chloride-Urea as a Pre-Treatment for Nanofibrillation of Wood Cellulose. Green Chem. 2015, $17(6), 3401-3406$

(19) Hammond, O. S.; Edler, K. J.; Bowron, D. T.; Torrente-murciano, L. Deep EutecticSolvothermal Synthesis of Nanostructured Ceria. Nat. Commun. 2017, 8 (May 2016), 1-7. 
(20) Cooper, E. R.; Andrews, C. D.; Wheatley, P. S.; Webb, P. B.; Wormald, P.; Morris, R. E. Ionic Liquids and Eutectic Mixtures as Solvent and Template in Synthesis of Zeolite Analogues. Nature 2004, 430, 1012-1016.

(21) Parnham, E. R.; Drylie, E. A.; Wheatley, P. S.; Slawin, A. M. Z.; Morris, R. E. Ionothermal Materials Synthesis Using Unstable Deep-Eutectic Solvents as Template-Delivery Agents. Angew. Chem - Int. Ed. 2006, 45, 4962-4966.

(22) Carriazo, D.; Guti, M. C.; Ferrer, M. L.; Monte, F. Resorcinol-Based Deep Eutectic Solvents as Both Carbonaceous Precursors and Templating Agents in the Synthesis of Hierarchical Porous Carbon Monoliths. Chem. - A Eur. J. 2010, 22 (3), 6146-6152.

(23) Liao, H.; Jiang, Y.; Zhou, Z.; Chen, S.; Sun, S. Shape-Controlled Synthesis of Gold Nanoparticles in Deep Eutectic Solvents for Studies of Structure - Functionality Relationships In. Angew. Chem 2008, 120, 9240-9243.

(24) Zhao, H.; Baker, G. A.; Holmes, S. Journal of Molecular Catalysis B : Enzymatic. "Journal Mol. Catal. B, Enzym. 2011, 72 (3-4), 163-167.

(25) Messa, F.; Perrone, S.; Capua, M.; Tolomeo, F.; Troisi, L.; Salomone, A. Towards a Sustainable Synthesis of Amides : Eutectic Solvents $\uparrow$. Chem. Commun. 2018, 4 (54), 81008103.

(26) Chen, J. P.; Isa, K. Thermal Decomposition of Urea and Urea Derivatives by Simultaneous TG/(DTA)/MS. J. Mass Spectrom. Soc. Jpn. 1998, 46 (4), 299-303.

(27) Mirny, V. N.; Prisyazhny, V. D.; Pushkarev, V. A. Hydrogen-Bond and Thermal-Stability of Mixed Carbamide Melts and Ammonium Halogenides. Ukr. Khim. Zh. (Russian Ed.) 
1987, 53, 1027-1029.

(28) Petrouleas, V.; Lemmon, R. M. X-Ray Diffraction Study of Choline Chloride's $\beta$ Form. $J$. Chem. Phys. 1978, 68, 2243-2246.

(29) Jacquemin, J.; Husson, P.; Padua, A. A. H.; Majer, V. Density and Viscosity of Several Pure and Water-Saturated Ionic Liquids. Green Chem. 2006, 8 (2), 172-180.

(30) Yadav, A.; Pandey, S. Densities and Viscosities of (Choline Chloride + Urea) Deep Eutectic Solvent and Its Aqueous Mixtures in the Temperature Range $293.15 \mathrm{~K}$ to $363.15 \mathrm{~K}$. $J$. Chem. Eng. Data 2014, 59 (7), 2221-2229.

(31) Xie, Y.; Dong, H.; Zhang, S.; Lu, X.; Ji, X. Effect of Water on the Density, Viscosity, and CO 2 Solubility in Choline Chloride / Urea. J. Chem. Eng. Data 2014, 59, 3344-3352.

(32) Su, W. C.; Shan, D.; Wong, H.; Li, M. H. Effect of Water on Solubility of Carbon Dioxide in (Aminomethanamide+2-Hydroxy-N, N ,N -Trimethylethanaminium Chloride ). J. Chem. Eng. Data 2009, 54, 1951-1955.

(33) Delgado-mellado, N.; Larriba, M.; Navarro, P.; Rigual, V.; Ayuso, M.; García, J.; Rodríguez, F. Thermal Stability of Choline Chloride Deep Eutectic Solvents by TGA / FTIR-ATR Analysis. J. Mol. Liq. 2018, 260, 37-43.

(34) Rodriguez Rodriguez, N.; Van den Bruinhorst, A.; Kollau, L. J. B.; Kroon, M. C.; Binnemans, K. Degradation of Deep-Eutectic Solvents Based on Choline Chloride and Carboxylic Acids. ACS Sustain. Chem. Eng. 2019, 7, 11521-11528.

(35) Schaber, P. M.; Colson, J.; Higgins, S.; Thielen, D.; Anspach, B.; Brauer, J. Thermal Decomposition (Pyrolysis) of Urea in an Open Reaction Vessel. Thermochim. Acta 2004, 
424 (1-2), 131-142. 